\title{
UJI AKTIVITAS PENANGKAP RADIKAL DPPH (1,1-difenil-2-pikrilhidrazil) ISOLAT ALFA MANGOSTIN KULIT BUAH MANGGIS (Garcinia mangostana L.)
}

\section{DPPH (1,1-diphenyl-2-pikrilhidrazil) RADICAL SCAVENGING ACTIVITY OF ALFA MANGOSTIN THAT ISOLATED FROM MANGOSTEEN RIND (Garcinia mangostana L.)}

\author{
Muhammad Da' $i^{\star}$, Fitriana Triharman \\ Fakultas Farmasi, Universitas Muhammadiyah Surakarta \\ abulathfi@gmail.com
}

\begin{abstract}
ABSTRAK
Manggis (Garcinia mangostana L.) merupakan sumber senyawa ksanton yang memiliti potensi sebagai penangkap radikal bebas. Penelitian ini bertujuan untuk mengeksplorasi isolat aktif sebagai antiradikal dari isolat alfa mangostin kulit buah manggis. Kulit buah manggis sejumlah $850 \mathrm{~g}$ dimaserasi berulang menggunakan pelarut heksan $(2,5 \mathrm{~L}$ selama dua hari) dan diisolasi dengan metode partisi menggunakan metanol hangat dan aquades (20:1). Analisis isolat yang didapat menggunakan Kromatografi lapis Tipis (KLT) dan High Performance Liquid Chromatography (HPLC). Aktivitas penangkap radikal ditentukan dengan menggunakan pereaksi DPPH (1,1-difenil-2-pikrilhidrazil) kemudian dihitung nilai Inhibitory Concentration (IC $C_{50}$ ), Efficiency Concentration $\left(E C_{50}\right)$, dan Antiradikal Power (ARP). Hasil ekstraksi diperoleh rendemen 0,41\%, sedangkan hasil isolasi diperoleh rendemen 0,33\%. Konfirmasi senyawa dengan KLT dan HPLC menunjukkan isolat belum murni. Pengukuran aktivitas penangkapan radikal DPPH diketahui bahwa isolat alfa mangostin memiliki aktivitas yang tinggi sebagai penangkap radikal DPPH dengan nilai $I C_{50} 13,68 \mu \mathrm{g} / \mathrm{ml}$, namun aktivitas penangkap radikalnya lebih kecil bila dibandingkan dengan vitamin $E\left(I C_{50} 12,50 \mu \mathrm{g} / \mathrm{ml}\right)$. Alfa mangostin dapat diisolasi dengan metode partisi metanol hangat : aquades (20:1).
\end{abstract}

Kata kunci: Manggis (Garcinia mangostana L.), Penangkap Radikal, DPPH

\begin{abstract}
Mangosteen (Garcinia mangostana L.) is a source of xanthon that have the potential as free radicals scavenger. This study was aimed to explore the antiradical activity of active isolate of alpha mangostin that isolated from mangosteen rind. Mangosteen rind $850 \mathrm{~g}$ was macerated a recurring use of solvent hexane (2.5 $L$ for two days) and isolated by partitioning method using hot methanol and distilled water (20:1). Analysis of isolates were obtained using thin layer chromatography (TLC) and High Performance Liquid Chromatography (HPLC). Radical scavenging activity was determined using reagent DPPH (1,1-diphenyl-2-pikrilhidrazil) then was calculated the value of Inhibitory Concentration (IC50), Efficiency Concentration (EC50), and antiradical Power $(A R P)$. The results obtained extract yield $0.41 \%$, while the isolate yield of $0.33 \%$. Confirmation of compounds by TLC and HPLC showed that isolate was pure. Measurement of DPPH radical activity showed that alpha-mangostin isolates had high activity as DPPH radical scavenger with IC50 value of $13.68 \mathrm{ug} / \mathrm{ml}$, lower than vitamin E (IC50 $12.50 \mu \mathrm{g} / \mathrm{mI})$.
\end{abstract}

Keywords: Mangosteen (Garcinia mangostana L.), DPPH radical scavenger

\section{PENDAHULUAN}

Radikal bebas adalah atom atau molekul yang mengandung satu atau lebih elektron tidak berpasangan dan sangat reaktif (Fessenden dan Fessenden, 1986) sehingga untuk menjadi stabil radikal bebas cenderung akan mengambil elektron dari molekul lain yang menimbulkan ketidaknormalan molekul lain dan memulai reaksi berantai yang dapat merusak jaringan.

Senyawa radikal akan merusak sel sehingga menyebabkan suatu penyakit seperti liver, kanker, dan kondisi yang berhubungan dengan umur seperti alzheimer (Hernani dan
Raharjo, 2006). Oleh karena itu diperlukan senyawa yang dapat meredam efek negatif dari radikal bebas yaitu antioksidan (Karyadi, 1997).

Antioksidan adalah substansi dalam kadar yang rendah mampu menghambat proses oksidasi. Dalam melindungi tubuh dari serangan radikal bebas, substansi antioksidan berfungsi untuk menstabilkan radikal bebas dengan melengkapi kekurangan elektron dari radikal bebas sehingga menghambat terjadinya reaksi berantai (Windono et al., 2001).

Salah satu sumber antioksidan yang berasal dari alam adalah tanaman manggis yang dalam bahasa Latin disebut Garcinia 
mangostana L dari famili Guttiferae. Kandungan kimia kulit manggis adalah ksanton, mangostin, garsinon, flavonoid, tanin (Heyne, 1987; Soedibyo, 1998). Senyawa ksanton banyak ditemukan pada dua famili dari tumbuhan tingkat tinggi yaitu famili Guttiferae dan Gentinaceae. Ditemukan 19 turunan xanton hasil isolasi dari buah manggis salah satunya alfa mangostin yang merupakan metabolit primer (Suksamrarn dkk., 2006). Penelitian terhadap aktivitas ekstrak metanol kulit buah manggis menunjukkan adanya aktivitas antiradikal terhadap DPPH (1,1-difenil-2pikrilhidrazil), sedangkan alfa dan gamma mangostin pada kulit buah manggis menggunakan metode ferric thiocyanate juga menunjukkan aktivitas antioksidan (Yoshikawa et al., 1994 cit Chaverri et al., 2008).

Penelitian ini dilakukan untuk mengetahui aktivitas penangkap radikal bebas isolat alfa mangostin kulit buah Manggis dengan metode DPPH.

\section{METODE PENELITIAN}

Bahan: Simplisia kulit buah manggis, $\mathrm{DPPH}$ (1,1-difenil-2-pikrilhidrazil), vitamin E (Sigma Co.), kloroform pro analysis (p.a) (E.Merck), metanol p.a (E.Merck), metanol absolute (for HPLC) p.a, heksan (E.Merck), kertas saring, aquadest, silika gel (E.Merck), dan TLC Plates Al Sheet Silica $F_{254}$ (E.Merck).

Alat: Glassware (Pyrex), corong buchner, spektrofotometer UV-Vis (UV Mini SHIMADZU), vaccum rotary evaporator, Ultrasonic stirer, bejana kromatografi, kuvet, vortex, mikropipet (Socorex), stopwatch, neraca anailitik (A\&D Co.Ltd.), High Performance Liquid Chromatography (HPLC).

\section{Jalan Penelitian}

Ekstrak kulit buah manggis yang diperoleh melaui maserasi menggunakan pelarut heksan dilarutkan dengan metanol hangat dan ditambahkan aquades DM (perbandingan metanol:aquades DM 20:1). Didinginkan dalam refrigerator pada suhu $4^{\circ} \mathrm{C}$ selama 24 jam. Dipisahkan antara kristal dengan cairan menggunakan kertas saring. Setelah diperoleh isolat, dianalisis menggunakan Kromatografi Lapis Tipis (KLT) dan High Performence Liquid Chromaogrphy (HPLC).

Aktivitas penagkap radikal ditentukan dengan metode DPPH. Isolat dengan konsentrasi tertentu ditambah $100 \mu \mathrm{LPPH}$ 0,4 $\mathrm{mM}$ dan metanol p.a hingga 1,0 ml. Campuran divortex selama 30 detik dan diukur absorbansinya pada $\lambda 517 \mathrm{~nm}$ terhadap blangko setelah operating time. Pengukuran absorbansi kontrol dilakukan terhadap $100 \mu \mathrm{l}$
DPPH dan $900 \mu$ metanol p.a. besarnya aktivitas penangkap radikal dihitung dengan rumus:

Persen (\%) penangkap radikal:

(absorbansi kontrol-absorbansi sampel) $\quad \times 100$ absorbansi kontrol

Penentuan aktivitas penangkap radikal dilakukan melalui perhitungan inhibitory concentration $\left(I C_{50}\right)$, efficiency concentration $\left(E C_{50}\right)$, dan antiradical power $(A R P)$. Hasil aktivitas penangkap radikal isolat alfa mangostin kulit buah manggis dibandingkan dengan vitamin $\mathrm{E}$.

\section{HASIL DAN PEMBAHASAN}

Pengujian kemurnian isolat alfa mangostin dilakukan dengan metode Kromatografi Lapis Tipis (KLT) dan High Performance Liquid Chromatography (HPLC). Hasil analisis KLT menunjukkan kesamaan profil kromatogram sampel uji isolat dengan profil kromatogram standar senyawa alfa mangostin. Sehingga dapat dikatakan bahwa sampel uji isolat mengandung senyawa alfa mangostin.

Pada analisis kualitatif menggunakan metode HPLC, menunjukkan Retention Time (RT) isolat maupun standar secara berturutturut yaitu 9,603 menit dan 10,528 menit. Hal ini dapat dikatakan bahwa dalam isolat tersebut mengandung alfa mangostin. Namun ditemukan dua puncak pada profil kromatogram isolat. Hasil uji secara keseluruhan menunjukkan bahwa isolat belum murni, dilihat dari profil kromatogram hasil KLT dan HPLC terdapat beberapa spot ataupun puncak. Hal ini dapat mempengaruhi potensi aktivitas penangkap radikalnya, dimana dari isolat yang didapatkan masih belum bisa ditentukan senyawa mana yang lebih poten bertanggung jawab terhadap aktivitas penangkap radikal.

Uji aktivitas penangkap radikal dilakukan dengan menggunakan metode DPPH (1,1difenil-2-pikrilhidrazil). Pengamatan dilakukan dengan melihat penurunan intensitas warna DPPH akibat direduksi oleh sampel uji.

Hasil pengukuran aktivitas penangkap radikal DPPH pada ekstrak heksan, isolat alfa mangostin dan vitamin $E$ secara berturut-turut adalah 21,22 $\mu \mathrm{g} / \mathrm{ml}, 13,68 \mu \mathrm{g} / \mathrm{ml}$, dan 12,50 $\mu \mathrm{g} / \mathrm{ml}$. Bila dibandingkan dengan aktivitas penangkap radikal oleh vitamin $\mathrm{E}$ diperoleh bahwa aktivitas penangkap radikal dari isolat alfa mangostin dan ekstrak heksan lebih kecil dari vitamin $\mathrm{E}$ (Tabel 1). Ekstrak heksan memiliki potensi aktivitas penangkap radikal paling rendah karena masih terdapat campuran berbagai macam senyawa yang relatif masih kompleks, sedangkan isolat mempunyai komposisi senyawa yang relatif lebih sederhana, dengan kandungan utama adalah alfa mangostin. 
Tabel 1-Hasil penentuan aktivitas penangkap radikal ekstrak heksan, isolat alfa mangostin kulit buah manggis dibandingkan dengan vitamin $\mathrm{E}$.

\begin{tabular}{|c|c|c|c|c|c|c|}
\hline $\begin{array}{l}\bar{\Phi} \\
\text { हू } \\
\text { ळू }\end{array}$ & $\begin{array}{l}\mathrm{IC}_{50} \\
(\mu \mathrm{g} / \\
\mathrm{ml})\end{array}$ & $\begin{array}{l}\mathrm{EC}_{50} \\
(\mu \mathrm{g} / \\
\mu \mathrm{g} \\
\mathrm{DPP} \\
\mathrm{H}\end{array}$ & $\begin{array}{l}\text { ARP } \\
(\mu g \\
\text { DPPH/ } \\
\mu g \\
\text { sampe } \\
\text { l) }\end{array}$ & $\begin{array}{l}\text { Rera } \\
\text { ta } \\
\mathrm{IC}_{\mathrm{so}} \\
(\mu \mathrm{g} / \\
\mathrm{ml}) \\
\pm \\
\mathrm{SD}\end{array}$ & $\begin{array}{l}\text { Rerata } \\
\text { EC }_{50} \\
(\mu g / \\
\mu g \\
\text { DPPH } \\
) \pm \text { SD }\end{array}$ & $\begin{array}{l}\text { Rerata } \\
\text { ARP }\end{array}$ \\
\hline \multirow{3}{*}{ 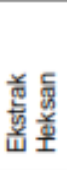 } & $\begin{array}{c}21,2 \\
9\end{array}$ & $\begin{array}{c}0,13 \\
6\end{array}$ & 735,29 & \multirow{3}{*}{$\begin{array}{c}21,2 \\
2 \\
\pm 0,8 \\
0\end{array}$} & \multirow{3}{*}{$\begin{array}{c}0,135 \\
\pm 0,005 \\
0\end{array}$} & \multirow{3}{*}{739,60} \\
\hline & $\begin{array}{c}21,9 \\
8\end{array}$ & $\begin{array}{c}0,14 \\
0\end{array}$ & 714,29 & & & \\
\hline & $\begin{array}{c}20,3 \\
8\end{array}$ & $\begin{array}{c}0,13 \\
0\end{array}$ & 769,23 & & & \\
\hline \multirow{5}{*}{ 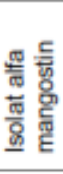 } & 13,7 & 0,08 & 1136,3 & \multirow{5}{*}{$\begin{array}{c}13,6 \\
8 \\
\pm 0,1 \\
0\end{array}$} & \multirow{5}{*}{$\begin{array}{c}0,087 \\
\pm 0,010 \\
0\end{array}$} & \multirow{5}{*}{$\begin{array}{c}1149,5 \\
5\end{array}$} \\
\hline & 7 & 8 & 6 & & & \\
\hline & 13,7 & 0,08 & 1149,4 & & & \\
\hline & 0 & 7 & 3 & & & \\
\hline & $\begin{array}{c}13,5 \\
8\end{array}$ & $\begin{array}{c}0,08 \\
6\end{array}$ & $\begin{array}{c}1162,7 \\
9\end{array}$ & & & \\
\hline \multirow{6}{*}{ ш } & 12,9 & 0,08 & 1204,8 & \multirow{6}{*}{$\begin{array}{c}12,5 \\
0 \\
\pm 0,4 \\
1\end{array}$} & \multirow{6}{*}{$\begin{array}{c}0,080 \\
\pm 0,003\end{array}$} & \multirow{6}{*}{$\begin{array}{c}1250,9 \\
0\end{array}$} \\
\hline & 7 & 3 & 2 & & & \\
\hline & 12,2 & 0,07 & 1282,0 & & & \\
\hline & 2 & 8 & 5 & & & \\
\hline & 12,3 & 0,07 & 1265,8 & & & \\
\hline & & & & & & \\
\hline
\end{tabular}

Aktivitas penangkap radikal dari isolat alfa mangostin kemungkinan berasal dari gugus $-\mathrm{OH}$ yang terikat pada cincin aromatik. Adanya inti aromatis pada senyawa fenol (gugus hidroksi fenolik) dapat mereduksi radikal bebas DPPH (hidrazil) menjadi bentuk netralnya (hidrazin) yang berwarna kuning.

Dilaporkan oleh Turkoglu et al., (2006) bahwa senyawa fenol dapat mengeliminasi radikal karena gugus hidroksinya. Senyawa fenolik bereaksi sebagai agen pereduksi, pemberi hidrogen, peredam oksigen singlet, dan juga sebagai pengkelat logam yang potensial (Kahkonen et al., 1999). Mekanisme antiradikal diawali dengan donor proton $-\mathrm{OH}$ fenolik kepada DPPH dan menghasilkan suatu radikal fenoksil (Gambar 1). Radikal fenoksil selanjutnya mengalami stabilitas resonansi terhadap ikatan rangkap terkonjugasi, sehingga menjadi radikal yang stabil dan tidak reaktif.

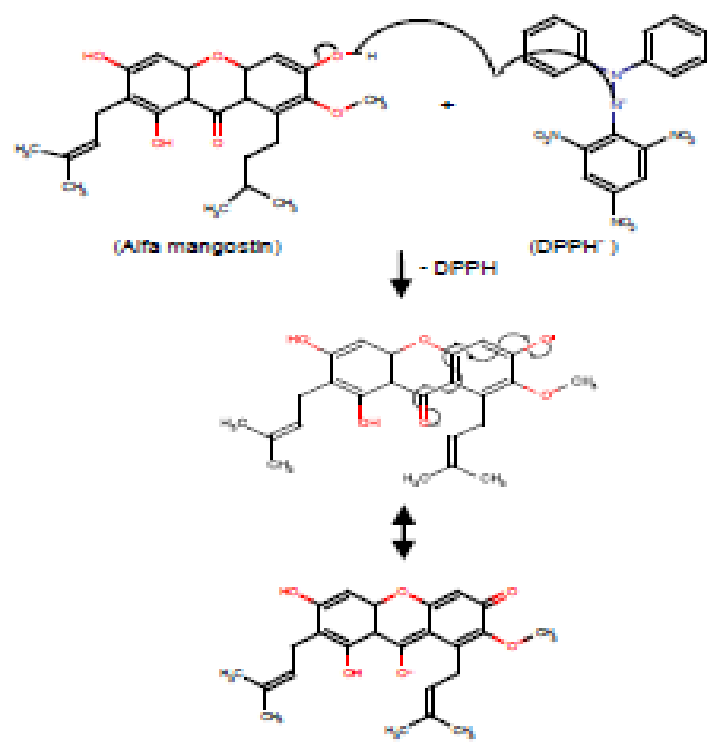

Gambar 1-Reaksi Radikal DPPH dengan Alfa Mangostin. Mekanisme antiradikal diawali dengan donor proton $-\mathrm{OH}$ fenolik kepada DPPH dan menghasilkan suatu radikal fenoksil yang mengalami stabilisasi resonansi terhadap ikatan rangkap terkonjugasi, sehingga menjadi radikal yang stabil dan tidak reaktif.

\section{KESIMPULAN}

Isolat alfa mangostin memiliki aktivitasyang tinggi sebagai penangkap radikal DPPH dengan nilai $\mathrm{IC}_{50} 13,68 \mu \mathrm{g} / \mathrm{ml}$, namun aktivitas penangkap radikalnya lebih kecil bila dibandingkan dengan vitamin $\mathrm{E}\left(\mathrm{IC}_{50} \quad 12,50\right.$ $\mu \mathrm{g} / \mathrm{ml}$ ). Alfa mangostin dapat diisolasi dengan metode partisi metanol hangat:aquades (20:1).

\section{SARAN}

Perlu dilakukan penentuan senyawasenyawa lain dalam kulit buah manggis yang berpotensi sebagai antiradikal selain senyawa alfa mangostin. Serta perlu diteliti lebih lanjut tentang potensi senyawa alfa mangostin selain sebagai antioksidan.

\section{DAFTAR ACUAN}

Chaverri, J. P., Rodriguez, N. C., Ibarra, M. O., and Rojas, J. M. R.,2008, Medical properties of mangosteen (Garcinia mangostana), Facultad de Quimica, Departemen Biologi, Universidad Nacional Autonoma de Mexico (Unam), Ciudad Univercitaria, Mexica.

Fessenden, R. J., and Fessenden, J. S., 1986, Kimia Organik, diterjemahkan oleh Pudjaatmakan, A. H., Edisi Ketiga, 223-224, Penerbit Erlangga, Jakarta.

Hernani dan Raharjo, M., 2006, Tanaman Berkhasiat Antioksidan, Penebar Swadaya, Jakarta.

Heyne, K., 1987, Tumbuhan Berguna Indonesia III, Penerjemah: Badan Penelitian dan Pengembangan Kehutanan, Yayasan Sarana Wahajaya, Jakarta, pp 1385 -1386.

Kähkönen M.P., Hopia A.I, Vuorela H.J., Rauha J.P., Pihlaja K., Kujala T.S., Heinonen M., 1999, Antioxidant activity of plant extracts containing phenolic compounds, J Agric Food Chem., 47(10):3954-62.

Karyadi, E., 1997, Antioksidan, Resep Sehat dan Umur Panjang, (http://www.indomedia.com/intisari/1997/juni/juni97.htm), Diakses 20 April 2009. 
Soedibyo, M., 1998, Alam Sumber Kesehatan, Balai Pustaka, Jakarta, pp 257-258.

Sudarsono, Gunawan, D., Wahyuono, S., Purnomo, I. A. G., 2002, Tumbuhan Obat II(Hasil Penelitian, Sifat-sifat, dan Penggunaan), Pusat Studi Obat Tradisional UGM, 91-92, Sekip-Utara, Yogyakarta.

Suksamrarn, S., Orapin, K., Piniti, R., Nititat, C., Nattapat, L., Apichart, S., 2006, Cytotoxic Prenylated Xanthones from the Young Fruit of Garcinia Mangostana, Chem. Pharm. Bull. 54(3) 301-305.

Turkoglu A., Kivrak I., Mercan N., Duru M.E., Gezer K. And Turkoglu H., 2006, Antioxidant and antimicrobial activities ofMorchella conica Pers. African Journal of Biotechnology. 5 (11), 11461150

Windono, T., Hendrajaya, K., Nurfatmawati, H., Soraya F., 2001, Uji Perendaman Radikal Bebas terhadap DPPH Dari Ekstrak Kulit Buah dan Biji Anggur (Vitis liniferol) Probolinggo Biru dan Bali, Artikel hasil penelitian Artocarpus, Vol. 1 Fakultas Farmasi UNAIR, Surabaya 34-43. 